\title{
Hearing Loss in Low Birth Weight Neonates: A Comparative Study at Nepalgunj Medical College and Teaching Hospital
}

\author{
Sharma $A^{1}$, Saxena RK ${ }^{1}$, Poudel DR ${ }^{1}$, Shrestha $K^{1}$
}

\section{ABSTRACT}

Introduction: Hearing impairment is the most common congenital abnormality that occurs in 1 to $4 / 1000$ newborns. It has a profound effect on their optimal development of language, speech and cognitive skill. Early detection in order to achieve effective treatment is essential. An association between low birth weight and hearing loss is commonly associated with multiple risk factors that can alter hearing in a synergistic fashion. Universal neonatal hearing screening programs have become widely implemented aiming for the screening, confirmation of the diagnosis and intervention by 1, 3 and 6 months respectively. Transient Evoked Otoacoustic emissions is one of the test found to be a quick, objective, non-invasive, accurate and easy test for early detection of this problem. Aim: Early detection of hearing loss in neonates focusing on low birth weight for early optimum rehabilitation. Methods: A comparative case control study conducted in 100 neonates under 2 groups. 50 neonates with low birth weight and 50 with normal birth weight who were born at NGMCTH, Kohalpur. Their hearing evaluation was done with Transient Evoked Oto Acoustic Emission (TEOAE). Results: The total referral rate was $12 \%$ and pass rate was $88 \%$. The referral rate in LBW group was 20 $\%$ and $4 \%$ in normal weight neonates. The pass rate in low birth weight was $80 \%$ and $96 \%$ in normal weight babies. Conclusion: Hearing impairment is a severe consequence in neonates with low birth weight. To decrease the economic and social burden of effects of hearing loss, it is assumed that newborn screening can immeasurably improve the future of newborn with early rehabilitation.

\section{Keywords: Hearing assessment, Low birth weight, Neonates, Transient Evoked otoacoustic emission}

\section{Authors:}

\author{
1. Dr. Anshu Sharma \\ 2. Prof. R.K. Saxena \\ 3. Prof. Dhundi Raj Paudel \\ 4. Dr. Kumar Shrestha \\ ${ }^{1}$ Department of Otorhinolaryngology, Nepalgunj Medical College and Teaching Hospital, Banke
}

\section{Address for Correspondance:}

\author{
Dr. Anshu Sharma \\ Department of Otorhinolaryngology \\ Nepalgunj Medical College and Teaching Hospital \\ Nepalgunj, Banke, Nepal \\ Phone: 9848031256 \\ E-mail: anshusa.regmi@gmail.com
}

\section{INTRODUCTION}

Hearing fulfills a fundamental role in the acquisition, development and maintenance of speech and language abilities. The hearing loss in infants is often irreversible, not only affecting optimal development of speech and language, but also the cognitive, intellectual, cultural and social development of the child. The incidence of moderate to profound congenital hearing loss is estimated to range from 1 to $4 / 1000$ live births and 5/100 for babies from neonatal intensive care units (NICU). ${ }^{1}$ The Joint Committee on Infant Hearing $(\mathrm{JClH})$ has set a goal and recommended High Risk Registry (HRR) to identify neonates at higher risk for hearing loss. Low birth weight (LBW) is one of the important HRR factor. National Institute for deafness and other communicative disorder (NIDCD) recommended Universal neonatal hearing screening (UNHS) for infants within the first
3 months of life. Congenital sensory neural hearing loss (SNHL) ranges from 1 to 3 per 1000 live births. Hearing loss of $30 \mathrm{db}$ or greater occurs in 3/1000 infants and bilateral severe to profound hearing loss occurs in $1 / 1000$ live births. ${ }^{2}$ According to the surveys conducted in different countries by WHO, around 0.5 to $5 / 1000$ neonates and infants have congenital or early childhood onset of SNHL. ${ }^{3}$ The number of people in the world who suffer from a disabling hearing loss has increased from 42 million to 360 million in 2010. ${ }^{4}$ In Nepal the prevalence of deafness is about $16.6 \%$. About $10 \%$ of them are unaware of their problem because of mild impairment and $7 \%$ of them are suffering with disabling impairment. ${ }^{5}$ Birth weight is an indicator of biological maturity affecting the newborns health and subsequent progression. 2/3 children with LBW are premature. ${ }^{6}$ The other causes of LBW are young ages, multiple pregnancies, previous LBW infants, poor 
nutrition, smoking, medication, malnutrition, heart disease or hypertension, untreated coeliac diseases, drug addiction, alcohol abuse, and insufficient prenatal care and certain environmental risk factors. The prevalence of bilateral moderate to severe hearing loss in LBW $(<2500 \mathrm{gm})$ neonates is approximately $2-4 \%$. The overall prevalence of unilateral and bilateral mild to severe hearing impairment in this high risk infant population is $10-100$ times higher than neonates without risk factors. ${ }^{7}$

In Nepal the rate of newborn with LBW is $11.9 \% .^{8}$ The LBW is an essential determinant of mortality, morbidity and disability. It has been possible to increase their survival but yet not their medical morbidity with the consequential auditory disability.

The physiological procedures for screening the neonates recommended by $\mathrm{JCIH}$ are $\mathrm{OAE}$ (Otoacoustic emission) and AABR (automated auditory brainstem response). OAE are lowintensity sounds that are generated by the cochlea. If there is damage to the outer hair cells then OAE are not evoked. The OAE have a reported sensitivity of $95 \%$, with a negative predictive value of $99 \%$ for identifying infants hearing loss. With the availability of OAE as a screening tool, screening of neonates has become more efficient, reliable and effective. ${ }^{9}$ OAE testing does have some limitations. It does not evaluate the inner hair cells (IHC), CN VIII, ascending central auditory pathway, or auditory processing function such as in auditory neuropathy spectrum disorder, so AABR is indicated..$^{10}$

\section{METHODS}

This was a comparative case control study, conducted from February 2018 to January 2019 in total of 100 neonates, 50 neonates with LBW and 50 neonates with normal birth weight (NBW) from NICU and postnatal ward of Nepalgunj Medical College Teaching Hospital (NGMCTH), Kohalpur, Banke, Nepal.

After random sampling hospital admitted newborns of either sex, with both LBW $(<2500 \mathrm{gm})$ or NBW with normal external auditory canal and intact tympanic membrane were enrolled for the study.

Exclusion criteria were newborns whose parents were not giving consent, External auditory canal abnormalities, retracted or bulged tympanic membrane, and presence of vernix or debris which could not be removed, babies having URTI, significant congenital malformation, family history of congenital hearing loss. The study population comprised of two groups: LBW neonates and NBW neonates. 50 neonates were included in each group fulfilling above mentioned inclusion criteria.

On the $2^{\text {nd }}$ or $3^{\text {rd }}$ day after birth, informed written consent, detail history about newborn was taken. Otoscopic examination, along with TEOAE was performed by portable analyzer device from MAICO Diagnostic GmbH, Salzufer 13/14, and D-10587. The frequency band were $1.5 \mathrm{KHz}, 2 \mathrm{KHz}, 2.5 \mathrm{KHz}, 3 \mathrm{KHz}, 3.5$ $\mathrm{KHz}$ and $4 \mathrm{KHz}$ and TEOAE stimulus intensity range was of 40 to
$70 \mathrm{~dB}$ SPL and maximum SPL of $90 \mathrm{~dB}$. The 'Pass-Fail' criteria were a SNR $\geq 6 \mathrm{~dB} S P L$, in three out of six frequency bands. The results was shown as either 'Pass', 'Refer' or 'Pass' in one ear and refer in another ear. In case of doubtful result, repeat tests were done up to a three times in order to reduce false positive results. Those who obtained 'Pass' were considered to have a hearing loss no more than $35 \mathrm{~dB}$ and those who obtained 'Refer' were referred to another center for AABR.

\section{STATISTICAL ANALYSIS:}

Chi Square test was used for analysis. ' $p$ ' value of $<0.05$ considered significant.

\section{RESULTS}

A total of 100 neonates underwent TEOAE test, out of which 56 were male and 44 were female. In LBW group, 25 (50\%) were male and 25 (50\%) were female. In normal group, 31 (62\%) were male and 19 (38\%) were female.

\begin{tabular}{|ccccc|}
\hline Study group & $>\mathbf{2 5 0 0}(\mathbf{g m})$ & $\mathbf{1 5 0 0}-\mathbf{2 4 9 9}(\mathbf{g m})$ & $<\mathbf{1 4 9 9}(\mathbf{g m})$ & Total \\
\hline LBW & 0 & 43 & 7 & 50 \\
\hline NBW & 50 & 0 & 0 & 50 \\
\hline Total & 50 & 43 & 7 & 100 \\
\hline
\end{tabular}

Table I : Frequency of weight distribution among the study group

\begin{tabular}{|c|c|c|c|}
\hline Study group & $<37$ (weeks) & $\geq 37$ (weeks) & Total \\
\hline LBW & 43 & 7 & 50 \\
\hline NBW & 17 & 33 & 50 \\
\hline Total & 60 & 40 & 100 \\
\hline \multicolumn{4}{|c|}{ Table II : Frequency of gestational age among the study group } \\
\hline Study group & Mean (weight) gm & \multicolumn{2}{|c|}{ Mean (gestational age) week } \\
\hline LBW & 1945.86 & \multicolumn{2}{|c|}{34.178} \\
\hline NBW & 2741.08 & \multicolumn{2}{|c|}{37.206} \\
\hline TOTAL & 2343.47 & \multicolumn{2}{|c|}{35.692} \\
\hline
\end{tabular}

Table III : Mean weight and gestational age among the study group

\begin{tabular}{|c|c|c|c|c|}
\hline Study group & Refer & Pass & Total & $P$ value \\
\hline LBW & $10(20 \%)(8 \mathrm{~B} / \mathrm{L}, 2 \mathrm{U} / \mathrm{L})$ & $\begin{array}{c}40 \\
(80 \%)\end{array}$ & $\begin{array}{c}50 \\
(100 \%)\end{array}$ & \multirow{3}{*}{0.014} \\
\hline Normal & $2(4 \%)(U / L)$ & $\begin{array}{c}48 \\
(96 \%)\end{array}$ & $\begin{array}{c}50 \\
(100 \%)\end{array}$ & \\
\hline Total & $12(12 \%)$ & $\begin{array}{c}88 \\
(88 \%)\end{array}$ & $\begin{array}{c}100 \\
(100 \%)\end{array}$ & \\
\hline
\end{tabular}

Table IV : TEOAE among the study group

In TEOAE $80 \%$ of neonates with LBW fell into PASS group and $20 \%$ of them into REFER group. Among the normal weight neonates, $96 \%$ fell into PASS group and only $4 \%$ into REFER group. The $p$ value was 0.014 which was statistically significant.

\section{DISCUSSION}

Hearing loss is referred as an epidemic of developing countries because of its high prevalence. Failure to intervene 
in time renders a severe threat to critical quality of life. Early identification and intervention can prevent severe psychosocial, educational and linguistic and cognitive development. Now early identification is defined as diagnosis as early as 3 months with intervention by 6 months of age. ${ }^{6}$ Although survival of high risk neonates is getting emphasis in national health policy of Nepal, their hearing screening is neglected.

This study was done to screen and compare the hearing impairment among the LBW and NBW neonates using TEOAE. In this study the referral rate was found to be $20 \%$ in LBW group and $4 \%$ in NBW group. This result was found to be similar to the study done by Korres SG et al ${ }^{1}$ in 2007 and Roth et al ${ }^{11}$ in 2006. However this study was found to be in contrast to the study done by Van Dommelen et al ${ }^{12}$ in 2015, where the referral rate was higher. This might be because, we used TEOAE only and they used $A A B R$. If OAE was used in combination with $A A B R$ then the referral rate might have decreased. Differences in pass rates reported in the literature are influenced by several factors. Preterm infants tend to suffer from noisy breathing and/or middle ear effusion or dysfunction, resulting in a high failure rate and requiring further or repeated examinations. Furthermore, TEOAE testing of NICU infants who were still on monitors was difficult. According to our protocol, TEOAE screening took place on $2^{\text {nd }}$ or $3^{\text {rd }}$ days after the birth and we usually didn't take much of neonates having nasogastric tubes. This may have contributed to the higher pass rates in our study. The present study confirms the great accuracy of neonatal screening for congenital hearing loss by means of TEOAE analysis, despite the fact that the possibility of false negative (hearing neuropathy) must always be considered. American Academy of Pediatrics have reported a prevalence of sensory neural hearing defects from 4.4-7.1 up to 50 times greater in premature infants in NICU. ${ }^{13}$ In this study, hearing loss was significantly associated with LBW, though the detailed data of results are not shown in this article, other factors were also associated with hearing loss. Those factors were low Apgar score, hyperbilirubinemia, ototoxic medications and prolonged mechanical ventilation.

LBW has been consistently identified as one of the high risk criteria for congenital hearing loss. In our study, statistical comparison between this group and controls showed significant differences in all TEOAE measures, indicating a degree of cochlear malfunctioning in LBW neonates.

\section{CONCLUSION}

This study shows that the newborn with LBW shows statistically significant positive co-relation with hearing loss. By preventing the causes of LBW for example like prematurity, malnutrition and others, by means of proper prenatal care, congenital hearing loss can be prevented. Joint efforts with maternal and child care programs should be launched.
It was concluded that the newborn hearing screening program could be implemented in hospital based programs as a part of standard medical care to provide early hearing rehabilitation and preventing disability.

\section{LIMITATION}

The limitation of this study was unavailability of AABR in our institution, which could have detected auditory neuropathy spectrum disorder.

\section{REFERENCES}

1. Korres SG, Balatsouras DG, Gkoritsa E, Kandiloros D, Korres GS, Ferekidis $\mathrm{E}$. The effect of very low birth weight on otoacoustic emissions. B ENT. 2007;3(1):15-20.

2. Norton SJ, Bhama PK, Perkins JA. Early detection and diagnosis of infant hearing impairement: Cummings otolaryngology $\left(5^{\text {th }}\right)$, Philadelphia;2010:2719

3. Informal Consultation on Prevention of Deafness and Hearing Impairment \& WHO Prevention of Deafness and Hearing Impairment. (2000). Future programme developments for prevention of deafness and hearing impairments : report of the third informal consultation, Geneva,11-12February 1999:

4. WHO global estimates on prevalence of hearing loss. cited 2018 Sep 28: https://apps.who.int/iris/bitstream/hand le/10665/260336/9789241550260-eng.pdf?sequence=1\&ua=1

5. Sharma B, Dahal M, Khadka B. Hearing impairment in Nepal. Hearing Impairment: Springer, Tokyo; 2004. 70-77.

6. Fortnum H, Davis A. Epidemiology of permanent childhood hearing impairment in Trent Region, 1985-1993. British journal of audiology. 1997;31(6):409-46.

7. Kok MR, Van Zanten GA, Brocaur MP, Jongejan HTM. Clickevoked otoacoustic emissions in very-low-birth-weight infants. 1994;33(3):152-64.

8. Yasmin S, Osrin D, Paul E, Costello A. Neonatal mortality of lowbirth-weight infants. Bulletin of the World Health Organization. 2001;79(7):608-14.

9. TP Waters, N Silva, JM Denney, AC Sciscione and DA Paul et al. neonatal hearing assessment in VLBW infants exposed to antenatal steroids. Journal of perinatology.2008;28.67-70.

10. Cunningham RF. Otoacoustic emissions: Beyond newborn hearing screening. Cited 20180ct2:https://www.audiologyonline.com/ articles/otoacoustic-emissions-beyond-newborn-hearing-838

11. Roth DA-E et al. Low prevalence of hearing impairment among very low birthweight infants as detected by universal neonatal hearing screening. Archives of Disease in Childhood: Fetal and Neonatal Edition. 2006;91(4):F257-F62.

12. Van Dommelen $P$, Verkerk PH, van Straaten HL, Dutch Neonatal Intensive Care Unit Neonatal Hearing Screening Working Group. Hearing loss by week of gestation and birth weight in very preterm neonates. The Journal of pediatrics. 2015;166(4):840-43.

13. Joint Committee on Infant Hearing. American Academy of Pediatrics Joint Committee on Infant Hearing, 1994 position statement. Pediatrics. 1995;95(1):152-56. 